\title{
Intradural extramedullary tuberculoma mimicking en plaque meningioma
}

\author{
Erdinc Ozek, A. Celal I plkcioglu, M ustafa Erdal \\ Department of Neurosurgery, Ministry of Health Okmeydani Education and Research Hospital, Istanbul, Turkey
}

\author{
Address for correspondence: \\ Dr. Erdinc O zek, \\ Neurosurgery Clinic, M inistry of \\ Health O kmeydani Education and \\ Research Hospital, Istanbul, Turkey. \\ E-mail: erdincozek@ gmail.com
}

DOI: $10.4103 / 0028-3886.51300$

\begin{abstract}
In this paper we report an 18 year old woman with an intradural extramedullary tuberculoma mimicking en plaque meningioma located in the thoracic region. The patient was operated via thoracic laminoplasty and tumor was totally resected. On the follow-up examination the magnetic resonance imaging demonstrated the total excision of the tumor. Here we describe a case of intradural extramedullary tuberculoma of the spinal cord as a complication of tuberculosis meningitis in a previously healthy young female.
\end{abstract}

Key words: Extramedullary, intradural, tuberculoma

\section{Introduction}

Intradural extramedullary tuberculoma of the spinal cord is a rare modality of tuberculosis and it is usually associated with tuberculosis meningitis. The pathogenesis is unclear, although a paradoxical reaction to antituberculosis medication is a reasonable possibility.

\section{Case Report}

A 18-year-old woman was admitted to our clinic with refractory dorsal pain and generalized weakness of both the lower extremities. She had a history of tuberculous meningitis of six months duration and was on antituberculous therapy. Her neurological examination revealed spastic weakness of both the lower extremities (grade 3/5) with exaggerated reflexes and bilaterally upgoing plantars. She also exhibited hypoesthesia below the T1 level. Magenetic resonance imaging (MRI) of the spinal cord showed an intradural extramedullary en plaque-shaped mass, extending from T1-9 vertebral column [Figure 1]. We performed a T1-9 laminoplasty and microscopic total removal of intradural extramedullary tuberculoma. Light microscopy of the lesion revealed granulomas with multinucleated and Langhans-type giant cells, confirming the diagnosis of the intradural extramedullary tuberculoma [Figure 2]. Postoperatively she had improvement in the motor strength of the bilateral lower extremities (grade 4/5). When reviewed at six months after the surgery, repeat MRI of the spinal cord confirmed the total resection

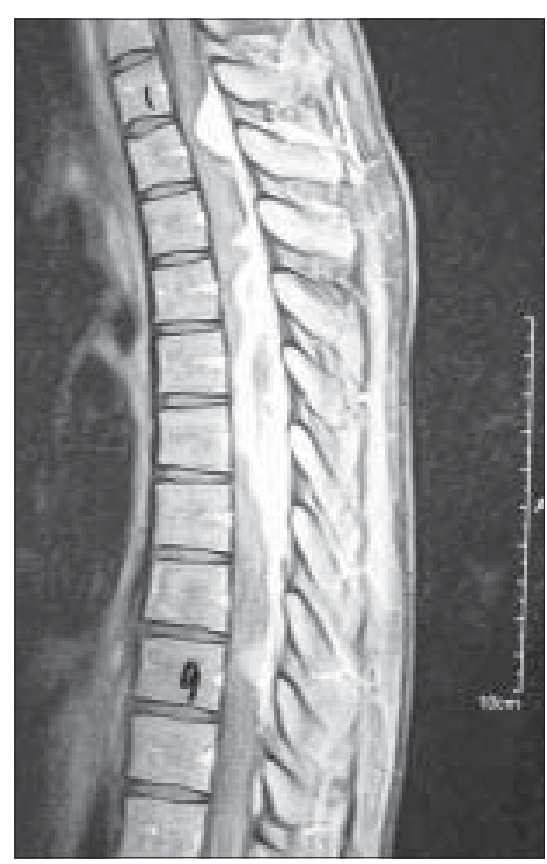

Figure 1: Pre-operative MRI

[Figure 3]. She was continued on anti-tuberculous up to a year.

\section{Discussion}

Dastur reviewed 74 cases of spinal tuberculomas and the lesion location was: Extradural in $64 \%$, arachnoidal in $20 \%$, intramedullary in $8 \%$, and intadural extramedullary in $8 \%{ }^{[1]}$ Intradural extramedullary tuberculoma is usually 


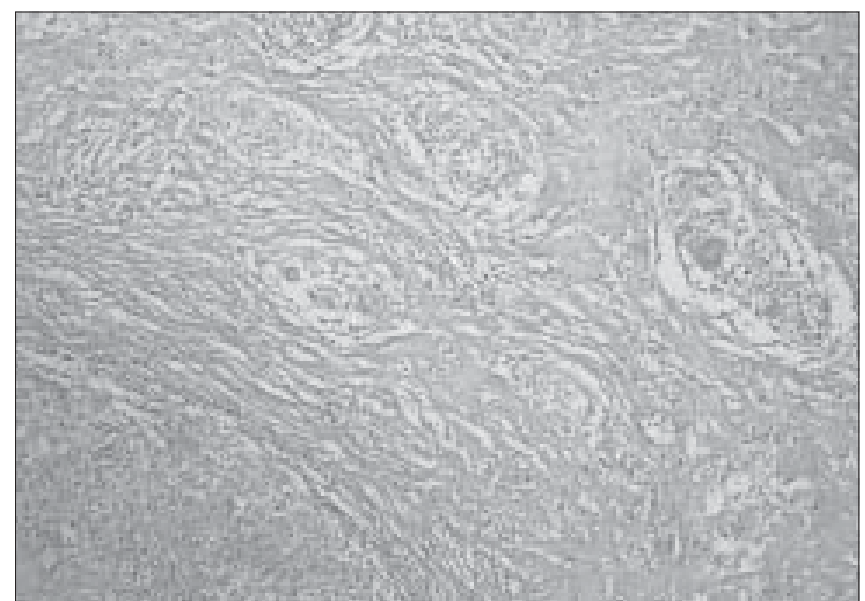

Figure 2: Histopathology revealed necrotic caseous center with Langhans giant cells $(H \& E \times 100)$

associated with tuberculous meningitis. An increase in the size of tuberculomas in patients undergoing antituberculosis treatment is believed to be due to paradoxical response. ${ }^{[2]}$ The paradoxical response to antituberculosis chemotherapy is thought to be due to the result of an immunological reaction..$^{[2]}$ Continuation of antituberculosis chemotherapy is usually sufficient when the paradoxical reaction develops in intracranial tuberculoma; however, in spinal tuberculomas prompt surgery may be indicated. ${ }^{[2]}$ Like in our case, en plaque intradural extramedullary tuberculomas are very rare lesions and only two cases reported in the literature so far. ${ }^{[2,3]}$ Because of the similar radiologic findings, intradural extramedullary tuberculomas should be considered in the differential diagnosis of the spinal meningioma and schwannoma. ${ }^{[2]}$ The case has been reported owing to the rarity of intradural extramedullary tuberculoma of the spinal cord as a complication of tuberculosis meningitis in a previously healthy young female.

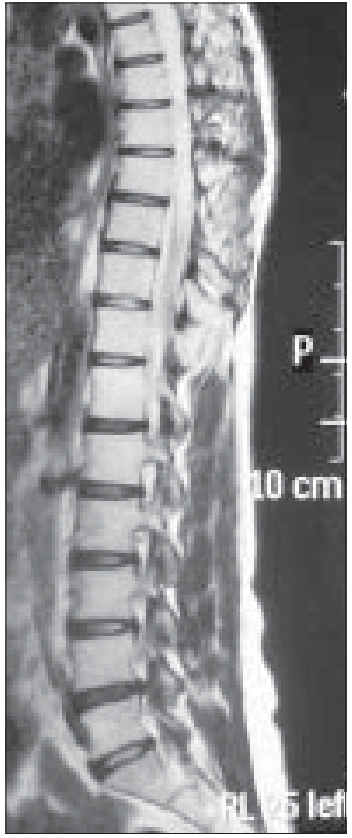

Figure 3: Postoperative MRI

\section{References}

1. Dastur HM. Diagnosis and neurosurgical treatment of Tuberculosis disease of the CNS. Neurosurg Rev 1983;6:111-7.

2. Muthukumar N, Sureshkumar V, Ramesh VG. En plaque intradural extramedullary spinal tuberculoma and concurrent intracranial tuberculomas: Paradoxical response to antituberculosis therapy. Case report. J Neurosurg Spine 2007;6:169-73.

3. Mirzai H. Tuberculoma of the Cervical Spinal Canal Mimicking En Plaque Meningioma. J Spinal Disord Tech 2005;18:197-9.

Accepted on 31-03-2009

Source of Support: Nil, Conflict of Interest: None declared. 